\title{
The Functioning of the International Oil Markets and its Security Implications
}

\author{
Giacomo Luciani*
}

No. 351, May 2011

\begin{abstract}
A bstract
The paper discusses the link between security of oil supplies and the functioning of international oil markets. It is argued that wide and frequent variations in price are in themselves a source of insecurity for individual consumers and national economies alike. Furthermore, the impossibility of predicting future prices discourages investment and increases the fragility of the system. The paper puts forward several policy proposals to reduce excessive price fluctuations and improve security of supply at reliable prices.
\end{abstract}

* Giacomo Luciani is Director of the Gulf Research Centre Foundation. CEPS Working Documents are intended to give an indication of work being conducted within CEPS' research programmes and to stimulate reactions from other experts in the field. The views expressed in this paper are those of the author and do not necessarily represent any institution with which he is affiliated.

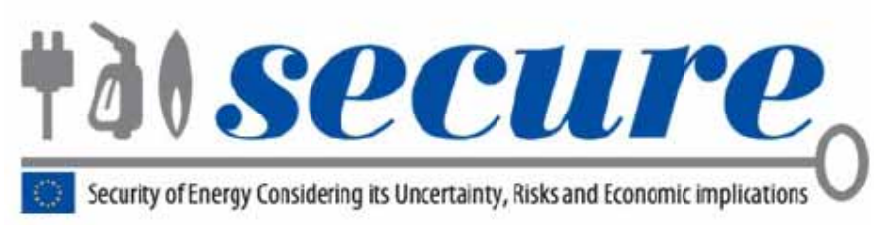

Research for this paper was carried out in the context of the SECURE project (Security of Energy Considering its Uncertainties, Risks and Economic Implications), funded by the European Commission under the Seventh Framework Programme. The project develops appropriate tools for evaluating the vulnerability of the EU to the different energy supply risks, and for promoting the optimisation of EU energy insecurity mitigation strategies, including investment, demand side management and dialogue with producing countries.

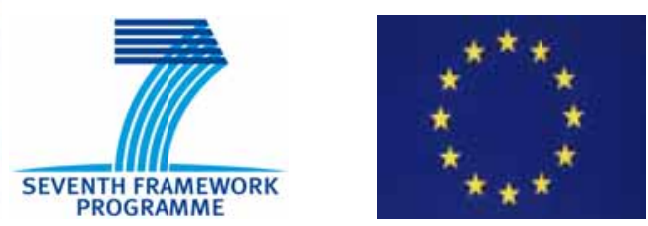




\section{Contents}

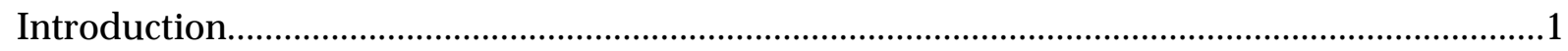

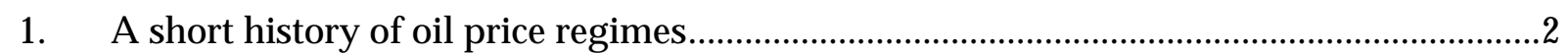

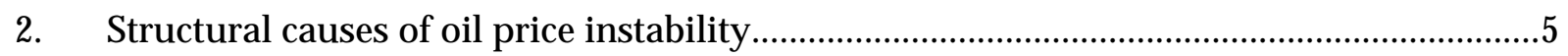

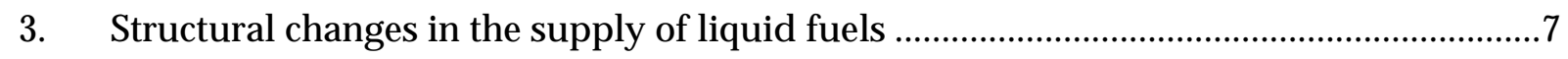

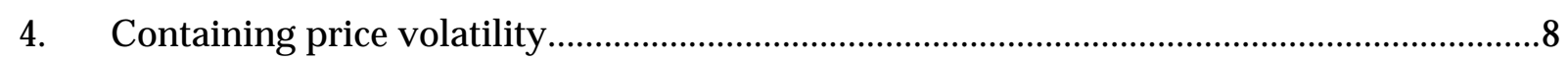

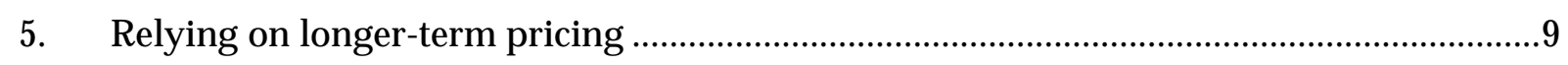

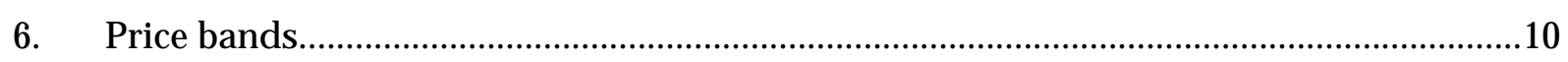

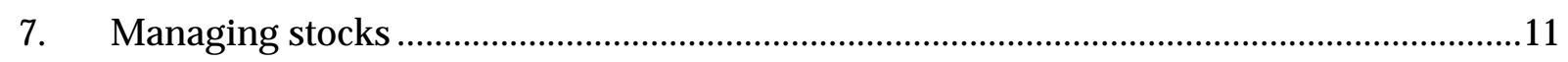

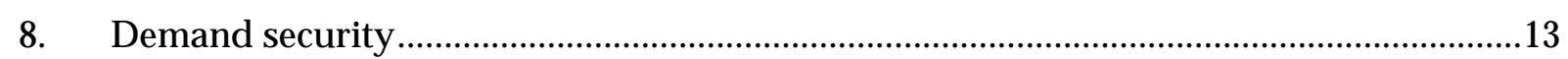

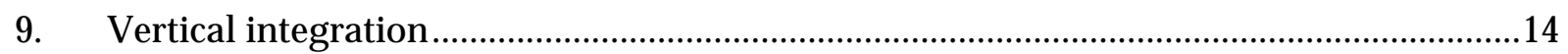

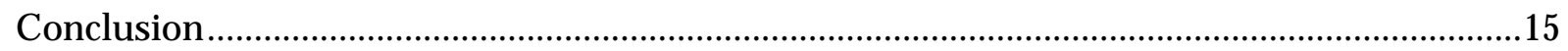

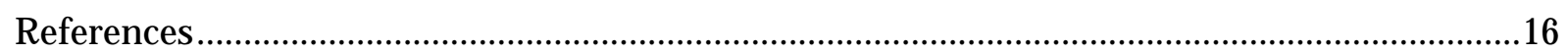




\title{
The Functioning of the International Oil Markets and its Security Implications
}

\author{
CEPS Working Document No. 351/ May 2011
}

\author{
Giacomo Luciani
}

\section{Introduction}

Energy security is primarily a function of investment. If investment in new capacity, logistics and transmission, and preparedness for emergencies is timely and adequate, energy security will be guaranteed.

Investment in a market economy is a function of the expected revenue stream, which in turn is a function of prices. Reliable and predictable price signals are a prerequisite of adequate investment. If prices are very volatile and/ or unpredictable, enterprises will not be confident enough to invest. Energy security will be imperilled.

A well-functioning market is therefore a key component of security. Ideally the market should generate stable and predictable prices, i.e. prices that can be modelled on the basis of structural factors within a price band which is narrow enough to allow enterprises to have a reasonably good idea of the revenue stream that their investment might generate.

The main obstacle to oil and gas security of supply is the growing volatility of prices and their fundamental unpredictability. This leaves enterprises exposed to very high risk and will discourage some of them. In these circumstances, it is to be expected that enterprises will tend to be conservative and underinvest.

Security itself is also dependent on prices. Customers feel secure if they can buy all the energy they need at prices that they can afford. A purely physical concept of security (meaning availability of the quantities of energy that are in demand at any given moment) has little meaning because demand varies with price. There always is a price at which demand will match supply - it may be a very high price, however, at which some final customers may not be able to satisfy their 'essential needs' Oil, specifically, has a global market and any supply interruption that one can think of is quickly translated into higher prices, this being the key mechanism for rationing demand and redistributing supplies among different bidders. In the end, oil is almost never physically unavailable.

But even 'essential needs' are a function of prices, in the sense that in the long run customers will adjust their consumption habits to the expected cost of energy and their disposable income. In the short term, such adjustments may be difficult, and what creates insecurity is the experience of price volatility, the fact of being surprised by sudden changes in price especially, of course, sudden price increases - which were not and could not be expected.

Hence energy security is as much a matter of perception as one of objective availability. Consumers make decisions on the basis of the historically prevailing level of prices: energy may be expensive or cheap - in the sense of absorbing a large or small share of their spending - and their lifestyles will adjust accordingly. Lifestyles and per capita energy consumption in Europe and Japan are quite different from those prevailing in North America because for decades energy has been relatively expensive in the former, and considerably cheaper in the latter. Nevertheless, consumers in Europe and Japan are not 
insecure because they had to devote a larger share of their income to energy than their N orth American counterparts - their level of consumption has adjusted to the price environment.

Well-functioning oil and gas markets therefore are not only a prerequisite of energy security through their influence on investment and future availability; they are also a component of security because volatile and unpredictable prices are part of the definition of insecurity.

This paper looks at the evolution of prevailing international oil price regimes over the past decades and at past attempts at stabilising prices (and reasons why these failed). This historical background helps us understand the causes of today's growing volatility and potential remedies for it. The current reference-pricing regime will then be introduced, and the debate on the causes of increasing volatility and whether the market responds to fundamentals or is dominated by speculators will be summarised. This debate is very much underway.

Next, we shall discuss the structural causes of volatility in the oil and gas markets. It is normally accepted that, even if the current market is reformed, volatility can be contained but not eliminated. What institutional arrangements can we envisage that will create enough long-term convergence in prices to ensure that investment is sufficient to meet future demand?

In the concluding section, I discuss how this relates to other aspects of the analysis of oil security, notably the geopolitical aspects and policies for strategic storage and cooperation with the exporting countries.

\section{A short history of oil price regimes}

The figure below is a well known and widely quoted representation of oil prices in nominal and real terms since the inception of the oil industry. The figure shows that oil prices were extremely volatile in the early days of the industry because output increased suddenly whenever there was a new discovery, then declined rapidly as fields were uncontrolled due to the law of capture in the US and poor technological understanding of petroleum geology.

The industry experienced one long stretch of stable oil prices, from the early 1920s to the early 1970s: a 50-year period of progressive expansion with slowly declining prices which was made possible by very large discoveries in the Middle East coupled with oligopolistic control on supplies by the so-called 'seven (or eight) sisters', the major international oil companies of the time. This control - albeit slowly yet systematically eroded by 'oil independents' and other newcomers - succeeded in guaranteeing the 'orderly' development of capacity in line with the rapid growth of demand. Oil supply security was guaranteed by the seven sisters, although not necessarily at the lowest possible price to the final consumer, nor with the fairest possible distribution of financial benefits between the various parties involved.

The seven sisters lost control of the oil market between 1969 and 1973. In 1969, Muammar Qaddafi seized power in Libya in a bloodless coup, overturning the Sanusi monarchy. Very soon, he started putting pressure on the companies by imposing unilateral production cuts. Some of the companies present in Libya had no significant assets elsewhere in the world and conceded to Libyan requests. Qaddafi found that it had become possible to play companies off against each other. This demonstrated that the bargaining power had shifted from companies to producing countries and led to the so-called 'Tehran-Tripoli agreements', then progressively to a complete shift of control from the companies to the producing countries.

The companies had unilaterally 'posted' a price for the crude they were producing. The role of the posted price was primarily to calculate the taxes due to the host governments, 
avoiding the controversies that would have arisen had 'market prices' been used instead. There was, in fact, no transparent and easily observed international oil market at the time.

In 1973, the power of fixing posted prices shifted from the companies to the exporting countries. This opened the door to a period of intense instability in prices which went from 1973 to 1985. Prices grew rapidly until 1980 and collapsed thereafter.

\section{Chart of crude oil process since 1981}

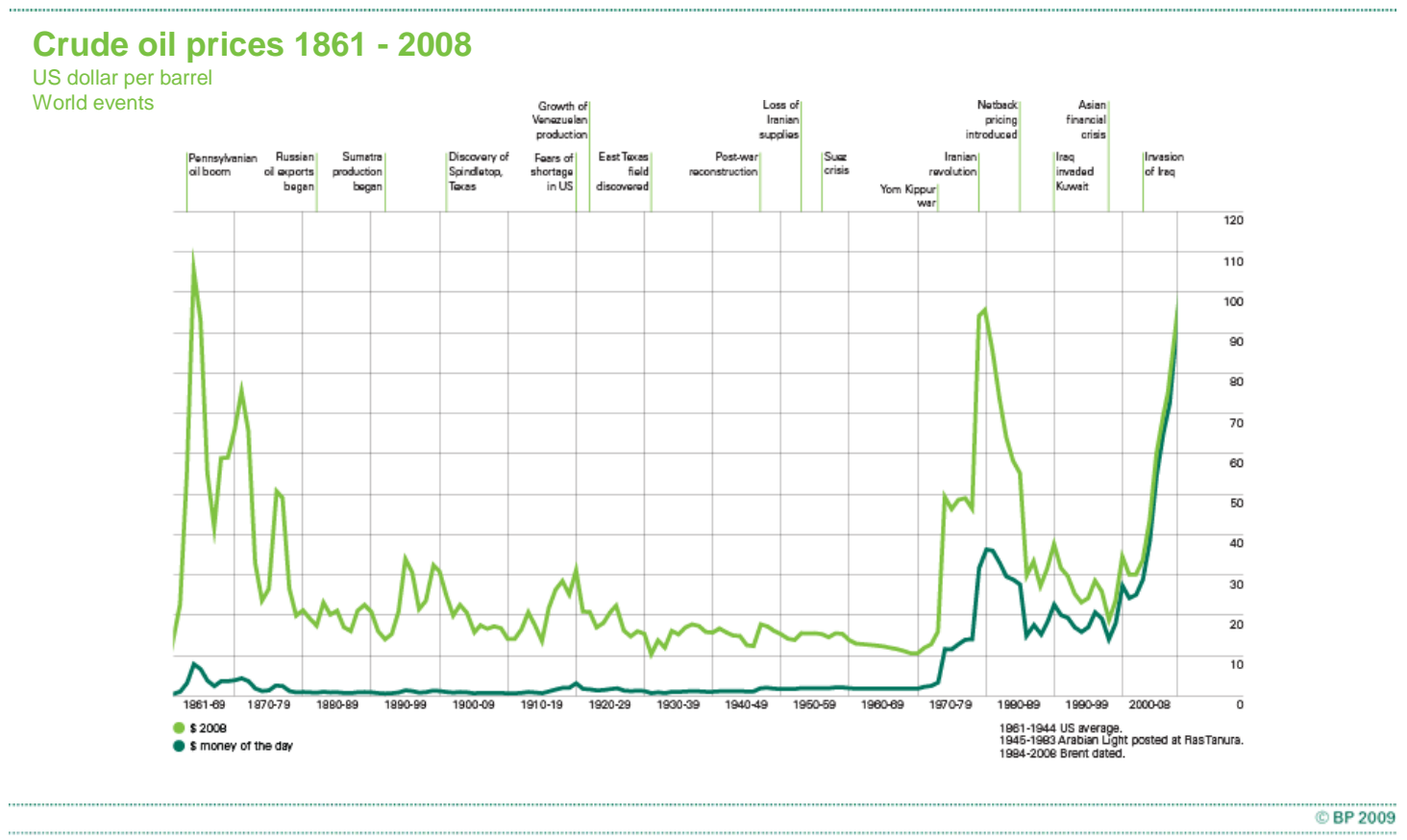

BP Statistical Review of World Energy June 2009

Prices increased in the 1970s because of political events: the Yom Kippur war of 1973, the Iranian Revolution of 1978-79 and the beginning of the Iraq-Iran war in 1980. Prices were pushed to historical highs and OPEC simply sanctioned the level that was generated by short-term panic buying and supply disruptions. Notwithstanding the opposition of some of its members, notably Saudi Arabia, a longer-term vision of OPEC's interests did not prevail: no consideration was given to the danger of demand destruction and growing non-OPEC supplies - although it was quite clear at that time that significant volumes of oil would be made available to the market from new producing regions, notably the North Sea, Alaska and Mexico.

OPEC attempted to defend its posted price by cutting back on production and enforcing quotas on its members. N on-compliance eroded OPEC's solidarity, al ready badly challenged by multiple conflicts between its Middle Eastern members.

In 1985, Saudi Arabia abandoned the posted price system and resorted to netback pricing. The netback price regime was short lived, lasting only about two years. It led to a collapse in crude oil prices, partly because OPEC quota discipline broke down and production increased, and partly because netback pricing tends to guarantee the refiners' margin and encourages refineries to run at full capacity, flooding the market with products and eventually reducing the netback value of the barrel. 
Thus began the era of reference pricing, which is the prevailing regime to this day. Reference pricing means that the price of crude oil that is not freely traded is indexed to the price of crude oil that is freely traded, plus or minus an adjustment factor, which is periodically reviewed by the producing country depending on market conditions. In this system, the producing country can manipulate the adjustment factor, but by far the biggest influence on the price of any non-traded crude comes from variations in the price of the benchmark crude to which it is tied.

Two markets have emerged as benchmark for all other crude oils - namely Brent in the UK and WTI (for West Texas Intermediate) in the US. This regime has proved more resilient in the face of political disturbances, but volatility has increased consistently and has exploded since 2007. The reason for increased volatility has been the progressive shift from referencing physical oil prices to referencing futures.

According to Robert Mabro:

Initially the marker prices were spot WTI, dated Brent, or spot ANS. The logic is that a marker price must be generated in a physical market where the transactions are sales and purchases of barrels of oil. Thus 'market-related' meant a relationship to prices arising at the margin of the physical market. This conforms to a fundamental economics principle that prices are determined at the margin. ${ }^{1}$

However, physical oil transactions became increasingly unreliable because of dwindling physical volumes and the ease with which the market could be influenced. As futures trading developed - originally as an appendix of the physical market intended to provide liquidity, but subsequently to attract trading many times in excess of that of the physical market - the balance of price discovery shifted from physical oil to futures.

We are now in the midst of a major controversy concerning whether 'speculation' is excessive, or 'investors' are simply providers of badly needed liquidity and better equipped to judge longer-term trends. Do oil prices nowadays respond to fundamentals or to speculation?

According to some, prices respond to fundamentals and indeed 'investors' or 'speculators' are better judges of long-term trends than 'commercial' traders, i.e. the oil companies. Throughout the 1990s and well into the early years of this century, major international oil companies maintained that the price of oil at \$18 per barrel (on average in the 1990s) was too high and would prove untenable. This opinion, it should be added, shaped the major companies' investment policies, leading to very conservative investment decisions and a preference for mergers and acquisitions over the development of new projects.

Against this view, a current of opinion insisted that oil is finite and production will inevitably peak. Various versions of the peak oil theory have been proposed at different times and heated controversy has characterised this debate.

The futures market were already signalling a tendency to increase in 2002 and early 2003. Prices had, in fact, increased in 2000 , but this spike had been deemed untenable by a majority of experts. And in early 2003 , the expectation was that prices would fall again, following the US and allies' intervention for regime change in Iraq, which would lead to an increase in Iraqi production and exertpressure on OPEC.

\footnotetext{
${ }^{1}$ Robert Mabro, "The International Oil Price Regime - Origins, Rationale and Assessment", Journal of Energy Literature, Vol. XI, No. 1, June 2005, pp 3-20.
} 
Instead, 2004 saw an unexpected increase in demand and further price increases. The futures market signalled a tendency towards higher prices through a persistent contango which, at the time, was deemed unjustified. The market was indicating its fundamental belief that oil would become relatively scarce as demand increased faster than supply. This is not necessarily the same as expecting a peak: all that is required is an expectation that supply will grow more slowly than demand. Today, most experts would agree that the market was right and preachers of low oil prices had been wrong.

However, in 2007 and even more so in 2008, the market was shaken by such violent swings that it is impossible to find a rational justification for the shifts in fundamentals. There was no dramatic demand increase or supply restriction to justify the doubling of prices between the beginning of 2008 and July of the same year, nor the dramatic collapse later in the year. Such swings can only be understood as part of the turbulence that hit financial markets, of which today's futures oil market is part and parcel. The price of oil is therefore highly exposed to financial markets vagaries' and disequilibria, and it has ceased to send a useful signal to corporate decision makers that can guide them in sanctioning long-term investment.

From the point of view of security of supply, what is the point of worrying about disruptions if their only impact is a major swing in oil prices, which could also happen if there is no major physical disruption?

Obviously, it is necessary to address the issue of price stability, and especially that of prices converging towards a long-term value, which may credibly be used for investment decisions.

\section{Structural causes of oil price instability}

Oil prices, like the prices of most commodities, are unstable because of well-understood structural causes.

Firstly, investment is the key cost component, while direct costs are relatively less important. This means that once the investment is made and the capacity created, it will be utilised even if prices fall well below the break-even point. It is only if prices fall below direct costs that the producer will consider shutting capacity, and even then it may be costly (in terms of immediate costs or forfeited long-term revenue) to shut capacity.

Secondly, investment gestation times are very long. For a while, the industry boasted that it was able to go from discovery to production in a much shorter time than in the past, but a few exceptional offshore examples in the Gulf of Guinea have since been overshadowed by numerous disaster stories - from the Gulf of Mexico to Sakhalin and Kashagan. ${ }^{2}$ Whether it is field development, pipeline construction or refinery construction, this is an industry in which five to ten years easily pass from the moment the investment is sanctioned to the moment it becomes operational. For all practical purposes, this means that investment is made with little or no knowledge of the returns it will bring when it becomes operational. True, the futures market can mitigate this risk and offers contracts and derivatives several years into the future, but liquidity at such distant maturities is thin and the feasibility of massive hedging of investment is problematic. In fact, very few major projects are financed with risk mitigation from the futures market.

\footnotetext{
2 The Kashagan oil field in the Caspian Sea offshore Kazakhstan was discovered in 2000. The cost of its development has ballooned and the time of first production has repeatedly been postponed. At the time of writing, the field is not yet in operation.
} 
Thirdly, and most importantly, both demand and supply are rigid in the short term. In econometric studies, short-term price elasticity has consistently been found to be very low, in fact very cl ose to zero ${ }^{3}$. Long-term elasticity is more significant, being estimated in a range of 0.5-0.6 for the OECD countries and much lower for the developing countries. Finally, authors who have repeated this estimate over time have found that price elasticity is declining - a consequence of the fact that other fuels have largely been substituted for oil uses in which substitution was easy.

The income elasticity of oil demand is higher than the price elasticity, meaning that oil demand can effectively be curbed only by reducing disposable income, i.e. through a recession.

The price elasticity of non-OPEC oil supply is also low, reflecting the points made above about investment being the main cost component and requiring long gestation. OPEC supply is of course considered a political variable and it is expanded or contracted depending on the organisation's price target and perception of market conditions - no structural elasticity can be measured.

The combination of rigid demand and rigid supply means that price signals generated by the market are not very effective in balancing the market. Or, conversely, it means that even very small shifts in the balance between demand and supply will provoke large changes in prices. In essence, this market can truly be balanced only through income and investment adjustments, which are slow and generally considered unwelcome. After all, the purpose of energy security is to maintain income and consumption levels, and concluding that demand and supply can only be balanced through declining income levels defeats the purpose.

Any discussion of the functioning of the international oil market with the aim of fostering security must therefore acknowledge that, in the short term, demand and supply are unlikely to be exactly in balance, and that this will cause wide swings in prices. The challenge is to aim at achieving a better balance of demand and supply in the longer term, so that shortterm price swings may be understood as oscillations around a central value, which is the long-term equilibrium price.

The search for a long-term equilibrium price is further complicated by our poor understanding of the dynamics of both demand and supply. In the case of supply, the most frequent procedure is attempting to estimate the non-OPEC component of the total and calculating the required OPEC contribution as the difference between projected global demand and projected non-OPEC supplies. However, estimates of non-OPEC supplies turn out to be significantly off the mark even when looking as little as one year ahead (or less). This is all the more surprising because when looking at the near future, we know very well which fields are in production and how they behave, and precious few surprises would seem to be possible. Instead, estimates of non-OPEC supplies are almost invariably off the mark and for the past few years they have been systematically in excess of recorded production.

The lack of success in predicting demand is in a sense even more surprising - because here we deal with literally billions of decision-makers, whose aggregate behaviour should be statistically predictable. In contrast, demand forecasts for any year are constantly adjusted (and by significant margins) as the year progresses, and in the end the distance from the

3 See, for example, Christopher Allsopp and Bassam Fattouh, "Oil Prices: Fundamentals or Speculation?", presentation to the Bank of England, 13June 2008, slides 10, 11 and 13. 
original expectation to the recorded result can easily be of the order of 1 to $2 \%$. With 0.05 price elasticity of demand, this alone justifies a $20 \%$ swing in prices...

Thus at any point in time we really have very little confidence about future demand and supply, and such lack of confidence fundamentally contributes to the perception of insecurity about energy supply.

\section{Structural changes in the supply of liquid fuels}

In the search for a longer-term equilibrium price for investment, we may have our task facilitated by some important changes which are occurring in the international oil industry.

Conventional crude oil is no longer the sole source of liquid fuels. Non-conventional sources will become increasingly important and the common feature of these sources is that they are primarily industrial processes in which output is much more easily predictable as a function of investment. The timing and production profile over time also are much more easily predictable.

Conventional oil is the realm of uncertainty. Exploration may or may not be successful, and a discovery may be a giant or a small field. The resources in place are never exactly known and estimates of reserves are constantly updated, generally upwards, but sometimes downwards. The time required for developing a field and the development cost per barrel of added capacity vary widely across the spectrum and are not always exactly predictable (Kashagan will serve as reminder for a long time). Finally, production from a field generally reaches a plateau rather quickly, but it is not easy to know for how long the plateau will last and how rapid might the decline be thereafter.

In contrast, most unconventional projects are much more predictable. The availability of the resource is not in question, be it oil sands, Orinoco bitumen or oil shale; in fact the available resource is so much greater than what is used as to be practically infinite. The difficulty is in the cost of the investment, with relatively minor operational issues involved - even the technology is not very demanding. At the time the investment is sanctioned, the investor knows with considerable precision what output he will get from the project and this output will be sustained for the life of the equipment. In this sense, non-conventional oil projects are much closer to a factory than to a mining operation, although they are a combination of the two. The limiting factor is the transformation capacity, not the availability of the raw material.

This is all the more true for projects transforming gas to liquids or coal to liquids. These are essentially petrochemical ventures.

The incremental capacity obtained through investment in non-conventional oil projects is relatively small compared with the investment and the global supply of crude oil. There is little danger that a sudden rush of non-conventional projects will cause an unexpected increase in supply and a collapse in prices which may undermine investment. Output increases from non-conventional projects will be gradual and very predictable.

As for conventional oil, predictability may also increase because the frequency of very large discoveries has dwindled to almost zero, while the number of declining regions is increasing. The probability of a sudden increase in capacity is therefore very low.

As declining fields come to account for a growing share of total oil reserves, the importance of enhanced oil recovery (EOR) increases. The effects of implementing EOR on declining fields cannot exactly be predicted, but the connection between investment and increased capacity is much tighter than with conventional methods. Also, as EOR methods are more 
widely adopted, the ratio of direct costs to investment costs may increase (this depends on the specific EOR technology adopted) and investment and production may become more responsive to prices.

From the demand side, it is not clear whether the development of alternatives to the use of fossil liquid fuels will increase or decrease price elasticity. As mentioned earlier, the evidence appears to be that the concentration of oil in those uses for which it is most difficult to find a substitute has further decreased elasticity. However, the appearance of alternatives in the transportation sector may generate greater responsiveness in demand if the consumer has directly or indirectly - the possibility of switching from one fuel or source of energy (or mode of transportation) to a different one.

\section{Containing price volatility}

In the light of extreme price fluctuations since 2007, the attention of politicians and experts has been drawn to the need to dampen short-term fluctuations and achieve greater reliability of prices.

The pendulum has swung back from the extreme position that favoured exclusive reliance on unregulated markets, to a position advocating the reining in of speculators and pursuit of a 'fair for all' price. ${ }^{4}$

The experience of the oil price yo-yo of 2007-09 has been sufficiently traumatic to lead to the emergence of a degree of political consensus on the need to dampen volatility and agree on a price that is acceptable to all sides. Expressions of concern have been voiced not only by the major OPEC exporters, but also by leaders of the major industrialised countries, notably the UK prime minister, Gordon Brown, President Sarkozy 5 and President Obama. It has been said that a consensus may be emerging to the extent that a 'fair' price might be in the region of $\$ 65-80$ per barrel.

Given these developments, the proposal has been made to establish an international committee that would decide on prices ${ }^{6}$ or a price band, ${ }^{7}$ as al ready happens with (national decisions on) interest rates. But how would such a consensus be implemented and enforced? How could producers and major consumers agree on sharing the burden of implementation (which presumably would require active market intervention)?

\footnotetext{
4 The Oxford Institute for Energy Studies held a conference on oil price volatility in October 2009 at St. Catherine's College. A summary of the discussion, which was held under Chatham House rules, was published in the Oxford Energy Forum No. 79 of N ovember 2009.

5 Gordon Brown and Nicholas Sarkozy (2009), "Oil Prices Need Government Supervision”, W all Street Journal, 8July.

6 Robert Mabro has proposed the creation of an independent commission backed by significant research capability and an international convention that would be expected to set a reference price for oil once a month. ENI, the energy company, has proposed the creation of a global energy agency "which might possess the tools to implement concrete initiatives as needed to stabilise the price of oil" (my translation of Scaroni's original speech, available in Italian from http:/ / www.eni.com/ en IT/ attachments/ media/ speeches-interviews/ italian-version-speech-scaroni-G8-energia-25-maggio2009.pdf).

7 See in particular, Bassam Fattouh and Christopher Allsopp (2009), "The Price Band and Oil Price Dynamics", 0 xford Energy Comment, July.
} 
Finally, it has been proposed that the major oil-producing countries - notably Saudi Arabia should take a more active role in the price discovery process and engage in direct sales of their crude oil through auctions of forward contracts for physical delivery and acceptance of a secondary market. 8

\section{Relying on longer-term pricing}

Even if speculation is curbed and short-term volatility is successfully dampened, it would be advisable to rely on price signals from longer-term maturities rather than on spot or frontmonth prices. Prices for longer maturities (3, 6 or 12 months) always fluctuate less than frontmonth prices and are inherently more stable because they are not influenced by short-term inconsistencies of demand and supply.

There is no overwhelming reason why prices to the final consumer should reflect the spot or front-month market. Refiners and retailers have the option of hedging forward and could very well be asked to guarantee a price to their customers or give significant advance notice of any variation. The market will not spontaneously generate such behaviour: no oil products retailer has considered competing by guaranteeing a price to its customers for a given period of time. The reason is simple: customers cannot be tied to a specific supplier. They would prefer the supplier that guarantees a price in the longer run for as long as that price is lower than the competition, and then switch to the competition as soon as it goes up. However, if regulations were adopted that required all suppliers to guarantee prices for a given period of time and/ or to announce changes with sufficient advance notice, the final consumer could not take advantage of prices that may be lower in the short term.

It is normally considered that the markets for oil products are either free or controlled, and the latter frequently means that prices that are kept artificially low because governments are reluctant to pass price increases for crude oil on to the final consumers. Indeed, the extensive reliance on price controls in developing countries, notably in the fast-growing Asian countries, has been singled out as one reason for the rigidity of demand relative to prices: demand is simply shielded from higher prices.

What is proposed here is not a system of price controls, but a set of regulations which would in essence encourage refiners and retailers to hedge on the futures market and lock in prices which they offer to their clients. Requesting retailers to 'post' prices which can only be changed with, say, three months' advance notice would probably yield the best results: competitors would be able to decide whether to follow the moves of the price leader and price competition would still be possible. If prices need to be guaranteed over a set period of time, adjustments will be more difficult and competition will be discouraged. In all cases, coordination leading to price fixing needs to be repressed.

The combination of advance notice and limits to the frequency of price changes would represent an increase of energy security for the final consumer per se. In theory, the final consumer could use the futures market and derivatives to reduce his risk and enhance his own security even in today's conditions, but in practice this is beyond the means of most consumers. Only large consumers, such as airlines or shipping companies, have done so, and they too are vulnerable to the threat of consumer disloyalty whenever their final prices are

8 Giacomo Luciani (2011), “From Price Taker to Price Maker? Saudi Arabia and the World Oil Market", Rahmania Occasional Paper No. 03. 
higher than the competition. Regulations for encouraging systematic hedging would contribute to energy security overall.

\section{Price bands}

The concept of a price band has been around for some time as a way to dampen volatility through a maximum and minimum price target, which would trigger action on the part of producers and/ or consumers as the market price approaches or crosses the extremes of the band. OPEC had a notional price band between 2000 and 2005. Robert Mabro, Christopher Allsopp and Bassam Fattouh of the Oxford Institute of Energy Studies have all argued in favour of a band. Behrooz Baik A lizadeh of the Iranian Ministry of Petroleum has written:

In its 109th ordinary meeting in March 2000, OPEC unofficially introduced its price band mechanism to the market. Within this mechanism, in the case of the average OPEC Basket crude price falling under $\$ 22 / \mathrm{b}$ [per barrel] for more than 10 successive working days, OPEC member states would be obligated to cut their daily production by $500,000 \mathrm{~b} / \mathrm{d}$ [barrels per day], and in the case of the price exceeding $\$ 28 / \mathrm{B}$ for 20 successive working days, OPEC would increase production by $500,000 \mathrm{~b} / \mathrm{d}$. Although OPEC took advantage of this mechanism only once, increasing production by $500,000 \mathrm{~b} / \mathrm{d}$ beginning on 31 October 2000 , and gave up the whole idea in January 2005, introduction of this mechanism affected the market psychologically and stabilised prices during the period that OPEC was not inclined to change prices beyond specific limits. ${ }^{9}$

The problem with any price band concept is the instrumentation of intervention required whenever the price approaches the limits. In the absence of appropriate instrumentation, it is not at all clear that the market psychology will be affected - indeed the market may be tempted to challenge the band and test the will of governments trying to enforce it.

A price band may be effective if both importing and exporting countries agree on its limits. It is not clear that such an agreement would ever be possible, although at present it appears that the target prices of both sides are very close. The interests of exporters and importers are in structural opposition, and convergence is likely to be an exception. However, it cannot be excluded that the industrial countries' concern for climate change and their desire to diversify their energy lead to a shift away from fossil fuels and oil in particular. Moreover, the exporting countries' fear that oil might be penalised as a consequence has indeed created a new order of priorities on both sides, so that the importers no longer wish to minimise, and the exporters no longer wish to maximise, the price.

Secondly, for the band to be a useful concept it would be necessary to enforce supply restraint on all exporters, not just OPEC. It may be argued that the threat of unrestrained expansion of non-OPEC supplies is fading away, because non-OPEC countries are unable to expand their production very much and, in fact, non-OPEC production has al ready peaked or reached a plateau according to some interpretations. Nevertheless, the importing countries should be ready to defend the lower limit of the band by imposing limitations on imports of oil from non-OPEC countries, if necessary.

In the opposite case of prices reaching the upper limit of the band, OPEC countries would obviously be called to use all of their available capacity to supply a tight market. However, if OPEC reached the limit of its capacity and the market remained tight, then the importing

9 Middle East Economic Survey (MEES), 9 February 2009. 
countries should be ready to ration domestic consumption, or use 'strategic' stocks (more on stocks later). In theory, this would also require concerted action on the part of all importers something that is guaranteed to be very contentious and difficult to achieve. In the absence of concerted action, free riding on the part of some would prevail.

A further difficulty has to do with revisions or adjustments to the band. If the band is adjusted very frequently - à la limite, in response to any price movement - it ends up being no restraint at all on volatility. At the same time, a band that is never adjusted is bound to become obsolete and untenable. Finding the optimal middle-of-the-road solution is highly subjective and controversial. If we add that this middle-of-the-road compromise would need to be collectively endorsed by both oil exporters and importers, we conclude that the task is very difficult indeed.

A price band might be useful if it is intended to limit price volatility only within a specified period of time, and involves a market-responsive automatic adjustment mechanism. For example, it may be envisaged that the price band would extend $\mathrm{x} \%$ above and below a central price equal to the average of observed prices in the previous year. In this way, if the price remains consistently close to the upper or lower limit of the band, the central price for the following year will be adjusted and the band moved up or down. The frequency of adjustment of the central price should be inversely proportional to the scope of the band. A system of very frequent adjustments (e.g. weekly adjustments of the central price to a moving average of the observed price over the previous $x$ months) might be compatible with a relatively narrow band (say $10 \%$ above or below the central price). This would serve the purpose of dampening very short-term volatility.

However, if the objective is to create a more reliable investment environment, priority should be given to less-frequent adjustments and a wider band. The beneficial effect on investment decisions of a broadly based agreement on a central price is likely to outweigh the uncertainty intrinsic in a relatively broader band.

Finally, as mentioned, the effectiveness of a band depends on its instrumentation. Supply restraint may take the form of output limits or the accumulation of stocks, which in turn could be used to counter excessive price increases. This leads us to the possibility of using intervention stocks in addition to strategic stocks, or some hybrid formula of strategic/ intervention stocks.

\section{M anaging stocks}

Strategic stocks are discussed in a separate paper within the SECURE project. The discussion shows the ambiguity of strategic stocks and the rules concerning their use, especially with respect to containing price variations.

In theory, strategic stocks are clearly distinct from commercial or intervention stocks. Strategic stocks are meant to be used in case of supply emergencies and to serve the purpose of guaranteeing energy security. Intervention stocks are meant to maintain prices at a fixed level or within a band. In practice, the distinction is blurred because the concept of energy security incorporates the notion of affordability and, therefore, some notion of a maximum acceptable price. Furthermore, emergencies or disturbances arising from geopolitical events such as wars or revolutions tend to be reflected in price levels more than in physically available supplies: in the end, demand always is matched by supply. Consequently, strategic stocks whose utilisation is based on a strict quantitative criterion (as is the case for the International Energy Agency's emergency response mechanism) tend never to be used. 
Intervention stocks are normally not very well regarded because in all cases in which the defence of a rigid price through the use of an intervention stock has been attempted, the stock facility eventually went bust. A rigid price regime invites speculation and eventually market forces overwhelm any stock that may have been be accumulated.

At the same time, it stands to reason that stocks should be accumulated at times when the price is declining or low, and liquidated at times when prices are high or increasing. Accumulating stocks even at times when prices are increasing appears intuitively irrational.

What this means is that institutions and facilities should be established to manage stocks in a flexible way and in the absence of a fixed price regime. If a band is broadly agreed, as discussed in the previous section, then institutions managing stocks will feel encouraged to sell when the price approaches the top of the band and buy when it approaches the bottom, but it might be dangerous to impose a rigid rule on the stock managers.

Should governments establish intervention stocks? In theory, managing stocks in a way which serves to maintain prices within a band is a profitable operation and might very well be undertaken by private investors. Investors may choose to buy and sell purely paper barrels or they may decide to hold physical barrels: the latter option is likely to have a beneficial effect on price stability. The objective of government regulations should therefore be to encourage private investors to hold physical stocks. Today, individual investors (the doctors and dentists of Chicago fame) and large financial investors shy away from physical barrels, and want to deal only in paper.

Encouraging the holding of physical stocks requires passing legislation that will make it easier to build and maintain storage. This is partly an issue of environmental and fiscal rules, partly an issue of market organisation. Physical storage operators (who shall be separate legal entities from the owners of the stored oil) should be empowered to issue certificates convertible into physical barrels: oil deposited into the storage would be exchanged for such certificates and certificates could be used to withdraw oil from storage. There is nothing exotic about this, but such a facility, and a market for the certificates that it might issue, does not exist.

Governments may well decide to facilitate this development by establishing an agency to build and manage the storage facility 10 - this can be established at the national or regional level or both - and issue certificates to oil depositors. The possibility of depositing oil would be open to all, including national oil companies of oil-exporting countries. Storage facilities could be established in all appropriate locations, not necessarily in the territory of the country or group of countries establishing them. In fact, it might be very interesting to establish large storage facilities at critical logistical junctures, such as the Suez Canal or the Malacca Strait, or in conjunction with pipeline projects which bypass these.

Major trading companies maintain storage facilities already today, but the phenomenon is limited 11 and not sufficient to influence crude-oil prices. Much larger storage facilities are

${ }^{10}$ Japan, A bu Dhabi and Saudi A rabia have an agreement along these lines. Japan has built storage in Japan itself that is offered to Abu Dhabi and Saudi Arabia free of charge to store its oil. The stored oil belongs to the producer but obviously Japan gains a degree of security because of this. See "Saudi A rabia to store oil in Japan", R euters, 23 December 2009.

11 In May 2010 Vitol sold $50 \%$ of its global storage business to Malaysia's MISC, a subsidiary of Petronas, the purpose being to attract additional equity to expand the business. Vitol being a privately held company owned by its employees, it faces difficulty in tapping the equity market and finance expansion. Financial Times, 17 May 2010. 
needed, and the private sector may not be attracted to build them. Nevertheless, per se the business of operating storage facilities may very well be profitable if investment in physical stocks develops as envisaged here.

Stored-oil certificates should be designed and regulated in such a way that they will be accepted as collateral by financial institutions. This would open the possibility for oil exporting countries to 'deposit' oil that they cannot sell at prices that they deem convenient, and to borrow funds to make up for the temporary shortfall in revenue. Of course, if assumptions about future prices are unrealistic, they may end up defaulting - but this should be a concern of the banks, as is the case for any credit issued against real collateral.

\section{Demand security}

In discussions of energy security, the producing countries have frequently stated that they are willing to engage in the investment that is required to meet expected future demand, but they need some demand security, i.e. assurance that the demand will be there as expected. In other words, security of supply begs security of demand.

In a free-market environment, there can of course be no assurance of future demand. Importing countries are at a loss to respond to the request for demand security because they possess no tools to guarantee demand. How can this problem be approached?

The establishment of storage facilities where oil could be deposited against certificates that may be discounted by financial intermediaries is of course already a step in the right direction. An agreement to consult and coordinate in the accumulation/ disposal of strategic stocks may also be of help. But neither is likely to be viewed as providing sufficient security of demand.

The gas industry historically solved the problem through take-or-pay contracts. These were said to place the burden of the volume risk on the buyer and leave the burden of the price risk on the seller. There is no denying that this arrangement, unpopular as it might have become, has allowed the implementation of some very ambitious investment projects and significant improvement in Europe's energy supplies. But these arrangements were only possible because prices were exogenously generated: gas prices were indexed to oil and oil products' prices in order to guarantee the competitiveness of gas in marginal uses.

In the case of oil, we cannot think in terms of take-or-pay contracts because the price needs to be internally generated. However, individual countries, including large ones, could conceivably conclude take-or-pay contracts and index the price to signals generated elsewhere in the world. For example, China or India could put in place take-or-pay contracts for volumes of Gulf oil, and index the price to Brent or WTI or some other traded market (e.g. the DME Oman contract). This would provide the Gulf producers with significant demand certainty and probably would be viewed with considerable anxiety by importers in the US, Japan and Europe. We are not quite there yet, it should be said, although the intensification of relations between the Gulf and the emerging countries in Asia does point in this direction.

The drawback of this arrangement is that it would divide the oil market into two segments one price making and the other price taking. It is to be expected that the smaller the pricemaking segment is in relation to the price-taking one, the higher the volatility on the price making segment would be. This is the same as saying that oil may be sold on the basis of long-term evergreen contracts or on a short-term basis: price is generated on the short-term market and this is where all potential demand/supply imbalances will be felt. Such 
imbalances may be minor when related to global demand and supply, but large when related to short-term trading only.

Today, we have a system that is very close to this: prices are indexed to traded markets that are a very small component of global physical supply and demand. The difference is that there are no proper take-or-pay contracts, only evergreen contracts which envisage neither an obligation to supply on the part of the seller nor an obligation to lift on the part of the buyer. In addition, the price directly reflects all the volatility of short-term markets. But an evolution towards take-or-pay contracts closer to those familiar to the gas industry is conceivable.

\section{Vertical integration}

Another potential way of encouraging longer-term investment in the industry is that of facilitating vertical integration. In the current downturn, the large, vertically integrated international oil companies have claimed that their investment plans are unaffected by the downturn and based on their long-term strategy.

This may or may not be true, of course. In past years, these same companies have frequently been criticised for allocating larger funds to purchasing their own stock and propping up the value of their shares than to industrial projects proper. They have also engaged extensively in mergers and acquisitions, a trend leading to the disappearance of several independent corporations - a loss of diversity which can only negatively affect the vitality of the sector.

At the same time, it is true that large integrated companies 'own' their market thanks to their retail operations and the oligopolistic nature of the business, They therefore enjoy a considerable degree of demand security, although they face the price risk and are exposed to price volatility as any other player in the industry. Large integrated companies also have a broader capital base and may be better able to continue funding investment projects out of internally generated resources than smaller independents.

Nevertheless, the 'old' large integrated companies remain vulnerable to the pressure from financial analysts and investors, who are typically interested only in 'returning value' to the shareholders in the short run. The functioning of financial markets does not encourage strategic thinking, as investors can enter and exit a stock at any time and are interested mostly in short-term appreciation. This is a problem for all industrial corporations, but it is an especially difficult problem for the oil companies, whose outlook is structurally longterm.

It is typical of the distorting signals that management receives from the financial market that all attention in recent years has been focused on cutting costs rather than guaranteeing the long-term growth of the company.

Thus let it be noted that security of energy supply is also dependent on the functioning of financial markets and the kind of signals that emanate from them. This is, however, not the place to enter into a discussion of how financial markets might be reformed to encourage longer-term thinking on the part of management.

In any case, the problem that affects the behaviour of the 'old' large integrated companies does not affect the 'new' integrated companies: these are the national companies of the major importers, which are venturing internationally in order to improve their security of supply, as well as the national oil companies of the exporting countries, which are investing downstream in order to gain better control of their markets. In both cases, ownership remains either entirely or to a large extent in the hands of strategic investors, frequently the State itself, and strategic thinking is encouraged rather than short-term profitability. 
The growing role of these companies is a factor increasing energy security, because they will invest with a long-term perspective. The activism (or shall we say 'aggressive' approach) of Chinese companies to acquiring reserves internationally has frequently been portrayed as being a threat to importers in the OECD - while it should be more properly understood as an example to follow. Equally, the drive of some national oil companies to integrate downstream, acquiring refining and retailing assets in the importing countries, has frequently been viewed as a threat, as if it entailed a further degree of dependence and loss of control, while in fact it should be viewed as improving security of supply, reinforcing the commitment of the supplier to service its own assets and keeping the market supplied.

Hence, vertical integration is important and it is good for energy security. The OECD countries should look into ways in which they may encourage more strategic behaviour on the part of the 'old' integrated majors, and preserve the sector by limiting the cannibalism represented by mergers and acquisitions. And they should welcome the downstream integration of the national oil companies of major producers, interpreting the will to invest as a commitment to supply.

\section{Conclusion}

This paper has argued that the functioning of markets is a key determinant of energy security. Geopolitical and other threats to physical supply may cause price shocks but, given historical experience, they are unlikely to cause any significant physical shortage. Therefore, insecurity is manifested by price shocks and price shocks are insecurity. But price shocks may very well originate in the absence of major disturbances to physical supplies, simply as runs originated by investors, or 'speculators', which the market does not correct because both demand and supply are rigid relative to prices.

Price volatility is therefore a threat per se, in many ways more important and more devastating than potential threats to physical supplies. The cost of price volatility is very high, much higher than the potential cost of possible disruption to physical supply; and it is significant not just now, but even more so in the long term, because of the depressive effect it has on energy investment generally.

Thus addressing price volatility is a key component of energy security policy.

Unfortunately, there is no easy recipe to dampen price volatility. This paper has reviewed several approaches that may reduce volatility, namely:

- $\quad$ Encouraging the freer trading of major crude-oil streams, notably those from the Gulf

- Increasing reliance on long-term pricing

- $\quad$ Enforcing an internationally agreed price band

- Managing stocks

- $\quad$ Offering demand security through take-or-pay contracts

- Encouraging vertical integration

None of these approaches is sufficient to stabilise prices on its own, but collectively they may very well succeed in reducing the extreme volatility that has been experienced since 2004 . Volatility will never be eliminated, because it is a structural feature of the oil industry, but it may be contained, and energy supply would be perceived as being much more secure. 


\section{References}

Aissaoui, Ali (2008), "Shaping Long Term Oil Price Expectations for Investment: is it Workable? Is it Achievable?", APICORP Commentary, Vol. 3, No. 11-12, NovemberDecember (http:/ / www.apicorp-arabia.com/ html/ cms/ media/ pdf/ research/ Commentary03112008.pdf).

Aissaoui, Ali (2009), "What Is A Fair Price For Oil And What Makes $\$ 75$ A Barrel Seem Fair?", A PICORP Commentary, Vol. 3, No. 11-12, November-December, Vol. 4, No. 4, A pril (http:/ / www.apicorp-arabia.com/ html/ cms/ media/ pdf/ research/ Commentary Vol 4 No 4 2009.pdf).

Allsopp, Christopher and Bassam Fattouh (2009), "The Price Band and Oil Price Dynamics", OIES Comment, July (http:/ / www.oxfordenergy.org/ pdfs/ comment 0107 09.pdf).

Allsopp, Christopher and Bassam Fattouh (2008), “Oil prices: fundamentals or speculation?", presentation at the Bank of England, 13 June.

Diwan, Roger, "The financialisation of the oil market and the increasing impact of financial institutions in the pricing of crude oil", Rahmania Occasional Paper, forthcoming.

Energy Charter Secretariat (2007), “Putting a Price on Energy - Pricing Mechanisms for Oil and Gas".

Fattouh, Bassam (2007), "The Drivers of Oil Prices: The Usefulness and Limitations of NonStructural model, the Demand-Supply Framework and Informal Approaches", OIES WPM 32, March (http:/ / www.oxfordenergy.org/ pdfs/ WPM 32.pdf).

Fattouh, Bassam (2008), "The Dynamics of Crude Oil Price Differentials", OIES WPM 36, January (http:/ / www.oxfordenergy.org/ pdfs/ WPM 36.pdf).

Fattouh, Bassam (2008), "Prospects of the DME Oman Crude Oil Futures Contract”, OIES Monthly Comment, March (http:/ / www.oxfordenergy.org/ pdfs/ comment 03081.pdf).

Fattouh, Bassam (2009), "Basis Variation and the Role of Inventories: Evidence from the Crude Oil Market", OIES WPM38, January (http:/ / www.oxfordenergy.org/ pdfs/ WPM38.pdf).

Fattouh, Bassam (2009), "Reinforcing Feedbacks, Time Spreads and Oil Prices", Oxford Energy Comment, March (http:/ / www.mees.com/ postedarticles/ oped/ v52n175OD02.htm).

Fattouh, Bassam (2009), "The Oil Market Through the Lense of the Latest Oil Price Cycle: Issues and Proposals", presentation at the OIES conference on Oil Price Volatility: Causes and Mitigation Strategies, 9 October.

Fattouh, Bassam (2010), “Price Formation in Oil Markets: Some Lessons from 2009”, Oxford Energy Comment, March.

Horsnell, Paul (2007), "The Dynamics of Oil Price Determination", Oxford Energy Forum, No. 71, November.

Kilian, Lutz (2010), “Oil Price Volatility: Origins and Effects”, WTO Staff Working Paper ERSD-2010-02, January.

Luciani, Giacomo (2011), "From Price Taker to Price Maker? Saudi Arabia and the World Oil Market", Rahmania Occasional Paper N o. 3, forthcoming. 
Luciani, Giacomo, “Price and Revenue Volatility: What Policy Options and Role for the State", G lobal Governance, forthcoming.

Mabro, Robert (2005), “The International Oil Price Regime: Origins, Rationale and Assessment", J ournal of Economic Literature, Vol. 11, No. 1, June, pp. 3-20.

OIES Summary of Conference on Oil Price Volatility: Causes and Mitigation Strategies, O xford Energy Forum, N o. 79, N ovember 2009.

US Interagency Task Force on Commodity Markets, Interim Report on Crude Oil (http:/ / www.cftc.gov/ stellent/ groups/ public/ @newsroom/ documents/ file/ itfinteri mreportoncrudeoil0708.pdf). 


\section{ABOUT CEPS}

Founded in Brussels in 1983, the Centre for European Policy Studies (CEPS) is widely recognised as the most experienced and authoritative think tank operating in the European Union today. CEPS acts as a leading forum for debate on EU affairs, distinguished by its strong in-house research capacity, complemented by an extensive network of partner institutes throughout the world.

\section{Goals}

- Carry out state-of-the-art policy research leading to innovative solutions to the challenges facing Europe today,

- Maintain the highest standards of academic excellence and unqualified independence

- Act as a forum for discussion among all stakeholders in the European policy process, and

- Providea regular flow of authoritative publications offering policy analysis and recommendations,

\section{Assets}

- Multidisciplinary, multinational \& multicultural research team of knowledgeable analysts,

- Participation in several research networks, comprising other highly reputable research institutes from throughout Europe, to complement and consolidate CEPS' research expertise and to extend its outreach,

- An extensive membership base of some 132 Corporate M embers and 118 Institutional Members, which provide expertise and practical experience and act as a sounding board for the feasi bility of CEPS policy proposals.

\section{Programme Structure}

\section{In-house Research Programmes}

\section{Economic and Social Welfare Policies}

Financial Institutions and Markets

Energy and Climate Change

EU Foreign, Security and Neighbourhood Policy

Justice and Home Affairs

Politics and Institutions

Regulatory Affairs

Agricultural and Rural Policy

\section{Independent Research Institutes managed by CEPS}

European Capital Markets Institute (ECMI)

European Credit Research Institute (ECRI)

\section{Research N etworks organised by CEPS}

European Climate Platform (ECP)

European N etwork for Better Regulation (ENBR)

European N etwork of Economic Policy

Research Institutes (ENEPRI)

European Policy Institutes N etwork (EPIN) 